\title{
CORPO, PODER E O ATO DE PARTEJAR: REFLEXÕES À LUZDAS RELAÇÕES DE GÊNERO ${ }^{1}$
}

\author{
BODY, STRENGTHAND LABORWORK: REFLECTIONS ON GENDER \\ RELATIONS \\ CUERPO, PODER Y ELACTO DE PARTEAR: REFLEXIONES A LA LUZ DE \\ LAS RELACIONES DE GÉNERO
}

Lúcia Helena Rodrigues Costa²

\begin{abstract}
RESUMO: O presente trabalho pretende contribuir com uma reflexão e discussão de alguns pontos sobre as questōes relativas ao corpo feminino e o poder que perpassam o ato de partejar, compreendido este como o momento no qual através do trabalho do(a) outro(a), uma mulher "dá a luz". Discute a perspectiva da dominaçăo masculina tomando como referência a violência simbólica em Bourdieu, propondo que a humanizaçäo do parto passa pelo aprofundamento da discussäo da dominaçăo de gênero, e não apenas do sexo ou da profissão de quem parteja.
\end{abstract}

PALAVRAS-CHAVE: gênero, parteira, violência simbólica.

Eu acho que se eu não fosse homem, as mulheres só queriam fazer parto comigo porque elas sabem que eu sou competente, tenho segurança naquilo que faço, (...) as parteiras coitadas, nảo sabem de nada, aprenderam assim como Deus criou batata $^{3}$. (AG/P.ent.no 19)

Eu não faço esse serviço de casa, eu dou toda assistência no parto, ai a parteira que está comigo faz um caldo, dá uma massagem, faz um chá, e eu fico lá até a mulher ganhar menino. Depois, o resto fica por conta da parteira. Esse negócio de dar banho em menino, serviço de casa, isso nảo é coisa pra homem! ${ }^{3}$ (AG/P ent.no 19)

\section{ALGUMAS CONSIDERAÇÕES INICIAIS}

Se inicio este trabalho transcrevendo a fala de um agente de saúde parteiro (Bessa; Ferreira, 1999, p.43) é por acreditar que de certa maneira ela nos dá uma dimensão do que significa o ato de partejar no imaginário de mulheres e de homens, e como este ato vem carregado de valores sociais que engendram o cotidiano. No transcorrer do trabalho farei uso dessa fala, no sentido de promover, ou talvez provocar, questionamentos que possam contribuir

1 Trabalho apresentado no Seminário Internacional Fazendo Gênero 4: cultura, política e sexualidade no século $X X \mid$.

2 Professora do Departamento de Assistência de Enfermagem do Curso de Graduação em Enfermagem da Universidade Estadual de Montes Claros (UNIMONTES). Mestranda do Programa de Pós-Graduação em Enfermagem da Universidade Federal de Santa Catarina( UFSC).

${ }^{3}$ Grifos do autor. 
para o desvelamento de alguns vieses que se propõem à "humanização" 4 do parto.

O discurso dominante que tem norteado as políticas de saúde (aqui no caso específico a saúde da mulher) com impacto total na última década têm apontado na direção da "humanização" do parto, buscando privilegiar ações que conduzam ao parto natural e ao aleitamento matemo: basta observar a ênfase que o ministério da saúde tem dado ao programa matemidade segura. ${ }^{5}$

Surgem dai vários questionamentos que emergem não só da minha condição de profissional de saúde engajada nas discussőes acerca dos rumos da atenção à saúde da mulher mas, especialmente, da minha condição de mulher que passou pela experiência do parto (três cesarianas) e deixou marcas da sensação bastante desagradável da completa incapacidade de decisão sobre o meu próprio corpo, além do incômodo medo, vazio e solidão na asséptica sala de um bloco obstétrico.

É óbvio que não vou aqui me colocar numa posição radical quanto à tecnologia médica do parto como apanágio de todos os males que permeiam o parto uma vez que o modelo de atenção à saúde é no todo perverso e excludente, e essa é uma discussão muito ampla que não está inserida como objetivo primeiro neste trabalho.

Apesar disso, não há como me furtar à evidência de que desde o seu nascimento a partir do século XVIII o hospital moderno tem se constituído em espaço de domínio médico (Foucault, 1985) e que portanto o parto hospitalar se situa sob os auspícios do poder-saber médico, não importando quem sejam as(os) parteiras(os). Essa conjuntura é um dos pontos-chave das reflexões propostas na perspectiva das relações de gênero que se dão no espaço intra-hospitalar. Em contrapartida, havendo uma redefinição do espaço reservado ao ato de partejar (casas de parto ou o próprio domicílio), quem seriam estas(es) parteiras(os)?

Quando chegamos a esse ponto deparamo-nos com uma discussão a esse respeito, enfatizando principalmente a "legitimidade" ${ }^{6}$ da participação masculina (Riesco,1999) como parteiros uma vez que o ato de partejar é historicamente ligado ao feminino. A essa discussão retornaremos no decorrer do trabalho, não só sob a ótica da historicidade dessa prática, mas principalmente buscando analisar se o poder que perpassa essa prática se situa apenas na prática médica hospitalizada, ou se trata, de maneira mais abrangente da dominação masculina.(Ferrand, 1986)

O aspecto acima colocado é de suma relevância, e é onde se insere a reflexão primeira deste trabalho: aqui o sexo vai dar lugar ao gênero, entendido este não apenas ao que está ligado à constituição biológica da pessoa, mas à construção da identidade social a partir do feminino e masculino (Louro, 1996) e com ele todo o arcabouço que gera as relações de dominação-subordinação entre homens e mulheres, inscrita nos seus corpos pela maternidade, reforçado pelo discurso sobre a mesma construído pelos homens e reforçado pelo discurso médico higienista do século XVIII (Corbin, 1997).

4 Toda vez que usar a palavra humanização relacionado a assuntos que remetem ao parto vou usar a palavra entre aspas por entender que a mesma está sendo usada de uma maneira muito vaga, isto é, destituída de um sentido que justifique seu uso tão indiscriminadamente.

${ }^{5}$ A este respeito o Ministério da Saúde tem divulgado um vasto material que contém, inclusive como ponto de partida para melhorar a assistência ao parto, o que denominaram de "oito passos para a implantaçăo de maternidade segura", que seria o início dos procedimentos norteadores para que um hospital conquiste o título "Maternidade Segura", o que o privilegiaria em relação aos outros inclusive nos valores de repasse de verba feito pelo SUS.

${ }^{6}$ Vou usar a palavra legitimidade no sentido de que se é ou năo justa a participaçăo masculina no ato de partejar. Já existe um debate a este respeito principalmente quando se trata do parto feito por năo médico( a este respeito ler a tese de doutorado de (Riesco, 1999). 


\section{UMA BREVE RETROSPECTIVAHISTÓRICA}

$O$ ato de cuidar de outras pessoas, incluído ai os cuidados com as mulheres durante 0 parto está ligado ao fazer feminino desde tempos imemoriais. A parturição, desenvolvida no âmbito doméstico, é atividade das mulheres que acumulam todas as tarefas ligadas não só à mulher, mas ao concepto, articulando cuidados que garantiram a sobrevivência da espécie desde a barbárie (Engels, 1975).

Melo (1978, p.10), em brilhante trabalho que historiciza a assistência ao parto e a marginalização feminina que culmina com a apropriação do saber das parteiras pela medicina hegemônica, masculina e científica a partir do século XVIII, nos diz em relação ao parto e à parturição:“Essa assistência, iniciada como uma forma de solidariedade feminina, desencadeou um processo gradual de acumulação de um saber essencialmente feminino sobre a parturição, originando as primeiras profissionais da história a lidar com o processo de parto: as parteiras."

O paradigma dominante baseado no poder temporal da igreja, que permeia a visão de mundo ocidental durante toda a Idade Média, trás no seu bojo os germes da intolerância à mulher, numa crescente misoginia que dentre outros fatores, vai desencadear a insanidade da caça às bruxas a partir do século XVI. E as bruxas são fatalmente ligadas ao seu fazer: são mulheres sábias, curandeiras, parteiras, geralmente oriundas da classe camponesa e que gozavam de grande prestígio social em suas comunidades (Melo, 1978).

Há estudos que citam o fato de que a tentativa de normalização e supervisão do trabalho da parteira até então exercido à margem do fazer médico, inicia-se a partir do século XV (Forbes,1964). A interferência religiosa que se faz muito clara quando impõe como condição básica para exercer o ofício. ser a mulher católica e não ter em seus antecedentes comportamentos que a desabonassem. É interessante observar que essa exigência de uma moralidade colocada à prova em detrimento da exigência de competência técnica, vai ser a tônica em todos os cursos de formação de parteiras sob a supervisão médica que surgem na Europa a partir do século XIX e inclusive no Brasil quando da criação da primeira escola de medicina, e a partir dai os cursos de parteiras (Pires, 1989).

Mas retomando a questão da caça às bruxas, é pertinente fazer algumas colocações com base na afirmação de Barstow (1995, p.137) a respeito da posição que as mulheres ocupavam:"Mas as mulheres tinham uma vantagem especial sobre o clero: como autoridades em matéria de sexo, elas afirmavam que era possivel o controle sobre a fertilidade, a concepção, a gravidez bem sucedida e o parto seguro. Curavam a impotência masculina e a infertilidade feminina, faziam abortos, forneciam contraceptivos aconselhavam sobre os problemas relativos aos cuidados com os recém-nascidos, afetando assim a taxa de nascimentos, um poder que as igrejas estavam determinadas a arrancar delas".

Foi exatamente nesse contexto, em que as igrejas tentavam se apropriar do conhecimento feminino essencialmente ligado ao corpo e às questões da reprodução humana, que emerge a medicina científica gerada nas universidades de acesso exclusivo aos homens e grande aliada em todo o processo de normalização do corpo feminino sexualizado e associado ao mal e ao demônio. Às igrejas e aos médicos vai se juntar, mais tarde, os interesses da nova burguesia ascendente que precisará dos corpos úteis em suas indústrias.

Afora estas questões até aqui colocadas, é oportuno dizer que ainda existia uma grande disputa dos párocos de aldeia com relação às parteiras: elas podiam pegar a criança primeiro, e num ritual anterior ao batismo ser oferecida a Lúcifer com a aquiescência da própria mãe, antes mesmo de ser batizada pelo padre em nome de Cristo (Barstow, 1995).

Todo o clima de horror que imperou durante a caça sistemática às bruxas, de certo contribuiu profundamente na construção da "rainha do lar", ou da mulher bela (Nahoum-Grappe, 1993) que deságua no estereótipo de mulher do século XIX destituída de qualquer princípio humanizador baseado na liberdade de escolha sobre o próprio destino. A mulher, assim como 
os negros e nativos das Índias e Américas, sentiram como ninguém o peso do medo e terror espalhado por um ocidente dito científico sob a inspiração, num primeiro momento da Renascença, e em seguida pelo lluminismo. Mais uma vez tomo as palavras de Barstow, que a meu ver ilustra a argumentação de (Scott, 1995) em favor da utilização do gênero como categoria de análise histórica."Foi apropriado que Margaret Lister, uma escocesa, tenha sido descrita em seu indiciamento 'como uma feiticeira, uma enfeitiçadora e liberada', liberada significando então o que significa hoje. $O$ fato de os historiadores no passado terem ignorado a evidente opressão ao sexo feminino nas perseguições por feitiçaria, e que alguns no presente continuem a culpar as vítimas, é tão extraordinário como os próprios fatos históricos". (Barstow, 1995, p.170)

Nessa perspectiva, com um rápido olhar ao que o passado nos legou principalmente nos últimos quatro séculos, talvez possamos entender melhor o que os dias de hoje nos diz em torno das atuais práticas ligadas ao ato de partejar e as possibilidades de superação dos problemas que nos afligem bem como, propor soluções para os conflitos existentes entre os sujeitos dessa ação.

\section{AS DUAS FACES DO PODER, CORPO FEMININO E PARTO}

Antes de mais nada gostaria de pontuar dois aspectos norteadores relacionados com o sub-título que propus para prosseguir a partir de agora, a análise neste trabalho.

O primeiro é o fato de ter adotado "corpo feminino" em detrimento de "corpo da mulher". Pode parecer num primeiro momento tratar-se apenas de questão semântica sem relevância para o contexto da proposta deste estudo. Mas ao contrário, quando me refiro ao corpo feminino estou me referindo não só ao corpo de mulher, mas ao corpo enquanto portador de uma gama de significados que evidenciam o gênero constituído através do habitus (Bourdieu,1995) que retomarei quando analisar o poder masculino.

O segundo ponto é o que chamei de as duas faces do poder, consideradas sob dois aspectos que ora se sobrepõem, ora se entrelaçam, e na maioria das vezes se confundem quando relacionadas ao parto: são as faces do poder masculino e do poder médico.

Iniciemos pelo poder médico que é o que nos vem à mente quando pensamos em parto dentro do contexto atual. Como já vimos anteriormente os médicos incorporaram a tocologia à sua prática oficial e tornou o trabalho das parteiras dependente deste modelo em todos os sentidos (Melo, 1978).

Barreira, em recente trabalho sobre a história da enfermagem brasileira, nos diz que no congresso dos práticos em 1922, a medicina no Brasil, à exemplo do que ocorria na Europa, se empenha em organizar-se enquanto profissão cientificamente posta num universo em que 0 discurso médico normalizador das ações dos sujeitos já havia se consolidado no século XIX, assim: "O saber médico é apresentado como esotérico e inatingível, e que reivindicam para a medicina o duplo status de ciência e de arte, o qual justifica a intervenção dos médicos sobre os corpos e a prescrição das ações e dos comportamentos, adequados à mulher e à enfermeira". (Barreira, 1999, p.128)

Interessante observar que as próprias enfermeiras enquanto mulheres estão submetidas à normalização e esta situação vai ser decisiva na maneira com que irão cuidar de si e dos outros (Barreira, 1999) e o que isto representa ainda hoje na assistência à saúde.

A assistência à saúde vai se medicalizando sistematicamente e sendo realizada cada vez mais no espaço hospitalar. Vale dizer que no caso específico dos partos, mesmo não sendo realizado pelo médico no hospital, é sob a sua óptica que ele se desenvolve e com o passar do tempo se sofistica e se instrumentaliza, chegando ao caos do número alarmante de cesarianas realizadas como se isso fosse o normal.

Bourdieu (1995) ao analisar a divisão do espaço entre os cabila pela ordem masculina, nos leva a refletir a respeito do que significaria esta divisão se nos aproximássemos das 
categorias de produção do capital simbólico, com relação ao espaço hospitalar de hegemonia masculina em meio a um universo feminino numericamente muito superior, cuja entrada maciça de mulheres na área médica nos últimos anos ainda não alterou.

Em seu trabalho intitulado "O Sexo do Hospital", Lopes (1996) nos mostra a presença esmagadora de mulheres não só em hospitais, mas na saúde como um todo e, principalmente, aponta as relações de conflito entre médicos (as) e enfermeiras (os). Ela nos diz que: "A relação que existe entre as práticas médicas (o tratar) e as da enfermagem (o cuidar), traduz, por exemplo, as ligações que existem entre natureza e legitimidade, entre gênero, classe e poder. A (re)construção cotidiana do poder médico e a dominação que exercem as práticas do tratar sobre as práticas do cuidar se articulam na dupla conjunção entre sexo e classe. Esta dupla conjunção define os conteúdos das primeiras-masculinas, científicas, portadoras de valores de verdadeira qualificação profissional — frente às segundas—relacionadas às "qualidades "femininas, empíricas, etc. (Lopes, 1996, p.82).

Visto sob este prisma, começamos a vislumbrar a fragilidade em que estão assentadas as bases do que se chama "Maternidade Segura". cujo objetivo principal é garantir uma assistência de qualidade durante o parto, uma vez que os atores continuam no mesmo espaço de hegemonia médica, e o que é pior, perpetuando a mesma visão do parto. Esta visão se concentra no útero e aos rituais patológicos do mesmo, em detrimento da vivência das mulheres e de suas comunidades de origem, em relação ao momento do nascimento (Monticelli, 1997). A respeito deste assunto é só consultar a literatura médica atual sobre gravidez de alto risco.

É fácil observar sob a ótica acima proposta que as(os) profissionais envolvidas(os) na assistência ao parto no espaço hospitalar, em especial as enfermeiras(os), necessitam antes de tudo reinterpretar seus próprios papéis enquanto profissão feminina, buscando através do aprofundamento e incorporação dos estudos de gênero a todas as categorias que compõem a Enfermagem hoje, vislumbrando um novo modelo que possa levar a uma efetiva "humanização do parto".

Neste momento algumas perguntas já se tornam prementes: e as mulheres, o que pensam de tudo isto? Em que medida elas têm participado na definição dos novos rumos da assistência ao parto? Existe diferença entre as propostas para as mulheres de acordo com sua classe social, ou seja, médicos para as privilegiadas e parteiras para as excluídas?

Há várias discussões que apontam neste caminho, ou seja, que as parteiras só devem existir onde não haja outra opção, dentro de um conceito muito estreito do que significa parteira, privilegiando sempre aspectos técnicos em detrimento dos aspectos culturais que envolvem o parto (Riesco, 1999).

Este fato agrava-se quando se trata de mulheres de classes sociais menos privilegiadas, cujo acesso aos serviços, além de lenta agonia, não as deixam em condições de decidir sobre aspectos relativos ao nascimento Valensi (1986) em artigo intitulado "Le Pouvoir Médical et les Femmes", faz referência a dificuldade que têm as mulheres imigrantes por não entenderem a linguagem do médico e o fato de estarem afastadas dos seus rituais ancestrais. Na verdade em nosso meio as mulheres entendem o discurso dos profissionais de saúde? A este respeito (Leal, 1995) nos apresenta um estudo significativo sobre fertilidade e práticas contraceptivas, em que as pessoas, apesar do discurso médico, continuam a utilizar seus referencias culturais. E quanto a entender a importância dos rituais na vida dos sujeitos e o valor que os mesmos possuem na construção das relações sociais, como profissionais de saúde, ainda temos um longo caminho a percorrer...

Falemos agora do significado do poder masculino e o que ele representa para o ato de partejar. Para tanto é preciso, antes de mais nada, entender o que difere efetivamente o poder masculino do poder médico, além de responder questões fundamentais como: qual a legitimidade do parteiro fora do âmbito hospitalar e em que medida o parto realizado em domicílio traz de volta a "humanização" do mesmo? 
Para tentar responder a estes questionamentos, retomo novamente as palavras de Bordieu (1995, p. 138), quando trata da dominação masculina: "Pelo fato de estar inscrito tanto nas divisões do mundo social ou, mais precisamente, nas relações sociais de dominação e exploração instituidas entre os sexos, como nos cérebros, sob a forma de princípios de di-visão que levam a classificar todas as coisas do mundo e todas as práticas segundo distinções redutiveis à oposição entre o masculino e o feminino, o sistema mítico-ritual é continuamente confirmado e legitimado pelas próprias práticas que ele determina e legitima."

Retomemos pois as palavras do agente comunitário de saúde parteiro do Acre, e através delas passemos a refletir sobre o significado do poder masculino. Quando ele diz "Eu acho que se não fosse homem as mulheres só queriam fazer parto comigo...", ele demonstra que ser homem significa um empecilho para o desenvolvimento de suas atividades. Minha experiência como docente em uma faculdade de Medicina em que o número de acadêmicos e acadêmicas era proporcionalmente igual, ao se tratar de questões relativas à saúde da mulher, podendo optar, elas sempre o faziam pelas acadêmicas. Existe o pudor fortemente ligado ao corpo feminino (principalmente quando se trata da genitália), e quem sabe no caso do parto domiciliar uma permanência dos ritos de parto como atributo da mulher no inconsciente feminino. É bom lembrarmos outro aspecto, quando ele diz "eu sou competente, tenho segurança naquilo que faço...", este é o discurso que também encontramos no caso dos médicos obstetras: a legitimidade de sua prática foi alcançada e possivel pelo discurso da cientificidade e da competência técnica (Melo, 1978). O final da primeira fala "... as parteiras, coitadas não sabem de nada, aprenderam assim como Deus criou batata", mostra a desvalorização e o desprezo pelo trabalho feminino, se comparado ao masculino, competente e seguro.

A segunda fala do mesmo agente em que ele encerra dizendo "...não é coisa pra homem!" nos coloca diante do significado da violência simbólica em que se concretiza a dominação masculina, na qual práticas consideradas menos honradas e domésticas (Bourdieu, 1995) como dar massagem, preparar chá, cuidar de crianças estão sempre relacionadas ao universo feminino e, portanto, desvalorizadas.

Neste momento toma forma definitiva o que tentei argumentar até aqui, e continuarei utilizando o exemplo do agente comunitário de saúde parteiro como norteador da argumentação. O agente comunitário de saúde dentro da hierarquia das profissões de saúde, ao contrário do médico que ocupa o topo, está na base da pirâmide, e mesmo assim, ao exercer atividade de parteiro reproduz as relações de poder que podemos observar na atenção que se dá à mulher em seu momento de dar à luz.

Para ele, o parto fica circunscrito na técnica de parturição que ele "domina muito melhor que as parteiras", e todas as outras atividades de menor importância são atribuidas às parteiras por não serem relevantes.

Nessa perspectiva temos o parto hospitalar que precisa se "humanizar", e o espaço domiciliar ou as casas de parto como alternativa a esta proposta de "humanização". Mas é justamente neste ponto que há a necessidade de romper com uma série de pressupostos sobre o parto e entendermos de vez uma situação concreta: tanto no hospital como no espaço doméstico ou alternativos não se muda nada se não entendermos e começarmos a propor novos caminhos para superar a dominação masculina.

Quando pensamos na legitimidade do homem parteiro, da maneira como ele foi situado no exemplo utilizado, penso ser ele completamente dispensável, mas esta é uma reflexão que farei a seguir, deixando bem claro o caráter aberto e não conclusivo da problemática que circunda as práticas de parto.

\section{À GUISA DE CONSIDERAÇÖES FINAIS}

Como disse anteriormente não pretendo apresentar uma conclusão e, sim, tomar possível 
lançar luzes sobre um assunto tão polêmico e tão fascinante, uma vez que trata do momento "mágico" do nascimento de um novo-ser. Mas é justamente ai que a meu ver se situa o início da discussão porque em nome do novo-ser muitas vezes se esquece do ser-que-gera, ou seja, a mulher, cuja saúde é sempre vista a partir do seu caráter reprodutivo, e paradoxalmente lhe é negado decidir sobre o que se passa em seu próprio corpo no momento do parto: os sujeitos que se apropriam deste ato se investem de um poder capaz de decidir por ela.

Quando se propõe a "humanização" do parto percebemos o quanto só a intenção sem uma leitura mais aprofundada do que isso significa pode cair no vazio dos discursos e nos casuísmos a que estamos acostumadas há tanto tempo na área de saúde. Penso desta forma por acreditar que nem a nível hospitalar, nem domiciliar haverá um avanço se não for possível romper com estruturas tão profundamente inscritas em nossos corpos e em nossas mentes e, por conseqüência, em todos os seguimentos de nossa vida, como é a dominação masculina.

A dominação masculina faz parte de uma teia muito mais sutil e ampla como podemos observar no dia a dia. Assim, quando disse antes que o modelo de parteiro conforme o exemplo que citei não nos interessa, quero dizer que isso se aplica a todas as instâncias do ato de partejar e não somente ao parto executado por não médico.

A entrada maciça de mulheres nos cursos médicos nas últimas décadas não nos garantiu uma assistência ao parto de mais qualidade, principalmente no sentido de resgatá-lo enquanto prática culturalmente dada passivel de uma série de representações rituais. Como se explica isto? Na verdade esta "aceitação" de todas as regras engendrada a partir de um mundo visto e construida por homens está internalizada em todos nós, inclusive e, principalmente, em nós mulheres.

Assim posso dizer que precisamos urgentemente repensar a "humanização" do parto a partir das mulheres enquanto sujeitos neste processo. O enfoque das discussões ligadas aos profissionais que devem ou não realizar parto precisam estar muito além das questões eminentemente ligadas à competência técnica: ela deve situar-se na dimensão do humano com um outro olhar.

Destarte não basta saber se serão médicos, médicas, enfermeiras, enfermeiros, parteiras ou parteiros tradicionais: o sexo biológico não importa. Deve contar a sensibilidade para entender que como seres humanos estamos em meio a relações construidas a partir do gênero feminino ou masculino antes mesmo de entendermos as diferenças sexuais, e que essas diferenças nos colocam dentro de um sistema hierarquizado e de domínio masculino passível de mudanças se desejamos para este milênio que desperta, uma sociedade mais justa e igualitária. Talvez tenha chegado a hora da revolução simbólica proposta por Bourdieu...

ABSTRACT: The present paper intends to contribute on a reflection and discussion of some issues
related to female's body and the strength present in laborwork, understood as the moment in which
through the support of another person, a woman "gives birth". It also discusses the perspective of
male dominance having as reference the symbolic violence from Bordieu, proposing that the
humanizing of labor demands a thorough discussion on gender dominance.

KEYWORDS: gender, symbolic violence, midwife

RESUMEN: El presente trabajo pretende contribuir con una reflexión y discusión de algunos puntos sobre las cuestiones relativas al cuerpo femenino y al poder implicito en el acto de partear, comprendido este como el momento en el que a través del trabajo del(la) otro(a), una mujer va a "dar a luz". Discute la perspectiva de la dominación masculina tomando como referencia la violencia simbólica en Bourdier. Propone asi, que la humanización del parto tiene que pasar por una profunda discusión de la dominación de género y no tan sólo del sexo o de la profesión de quienes partean.

PALABRAS CLAVE: género, partera, violencia simbólica 


\section{REFERÊNCIAS BIBLIOGRÁFICAS̀}

BARREIRA, I. L. Contribuição da História da Enfermagem Brasileira para o desenvolvimento da profissão. Revista de Enfermagem da Escola Anna Nery, v.3, n.1, p.125-141, abr. 1999.

BARSTOW, A. L: Chacina de feiticeiras: uma revisão histórica da caça às bruxas na Europa. Rio de Janeiro: José Olímpio, 1995.

BESSA, L. F.; FERREIRA, S. L. Mulheres e Parteiras: contribuição ao estudo do trabalho feminino em contexto domiciliar rural. Salvador: GRAFUFBa, 1999.

CORBIN, A. O Segredo do individuo In: PERROT, M. (Org.) História da Vida Privada: da revolução francesa à primeira guerra. Säo Paulo: Companhia das Letras, 1998. p. 419-501.

BORDIEU, P. A. Dominação Masculina. Educaçäo e realidade, v. 20, n. 2, 133-184, jul./dez. 1995.

ENGELS, F. A Origem da família da propriedade privada e do estado. Rio de Janeiro: Civilização Brasileira, 1975.

FERRAND, M. Les "bénéficies"de la médicalisation de la procréation In: VILAINE, A. M. et al. (Org.) Maternite en Mouvement: les femmes, la reproduction et les hommes de science. Montreal: EditionsSaint-Martin, 1986. p.171-174

FORBES, T. R. The Regulation of English Midwives in the Sixteenth and Seventeench Centuries. Hist. Med. Journal, v. 8, p. 235-244, 1964

FOUCAULT, M. Microfísica do poder. 5. ed. Rio de Janeiro: Graal, 1985.

LOPES, M. J. M. O sexo do hospital In: LOPES, M. J. M. et al. (Org.) Gênero \& Saúde. Porto Alegre: Artes Médicas, 1996. p.76-105.

LEAL, O. F. Sangue, fertilidade e práticas contraceptivas In: LEAL, O. F. (Org.) Corpo e significado: ensaios de antropologia social. Porto Alegre: Editora da Universidade/UFRGS, 1995. p.13-36.

LOURO, G. L. Nas Redes do Conceito de Gênero. In: LOPES, M. J. M. et al. (Org.) Gênero \& Saúde. Porto Alegre: Artes Médicas,1996. p.7-18.

MELO, V.H. O processo histórico de assistência ao parto e a marginalização feminina. Belo Horizonte: Núcleo de Estudos e Pesquisas Sobre a Mulher, UFMG, p. 9-36, 1978.

MONTICELLI, M. Nascimento como um rito de passagem: abordagem para o cuidado às mulheres $\mathrm{e}$ recém-nascidos. São Paulo: Robe, 1997.

NAHOUM-GRAPPE, V. A mulher bela. In: DUBY, G. (Org) História das mulheres. São Paulo: Companhia das Letras, 1995. v. 3, p.121-139.

PIRES, D. A hegemonia médica na saúde e a enfermagem. São Paulo: Cortez, 1989.

RIESCO, M. L. G. Que Parteira é essa? São Paulo, 1999. Tese (Doutorado) Escola de Enfermagem da USP.

SCOTT, J. Gênero uma categoria útil de análise histórica. Educação e realidade, Porto Alegre, FACED/ UFRGS, v.16, n.2, jul./dez. 1995.

VALENSI, J. Le Pouvoir Médical et les Femmes In: VILAINE, A. M. et al. (Org.) Maternite en Mouvement: les femmes, la reproduction et les hommes de scienc. Montreal: Editions Saint-Martin, 1986. p. $168-170$

Recebido em outubro de 1999

Aprovado em junho de 2000 